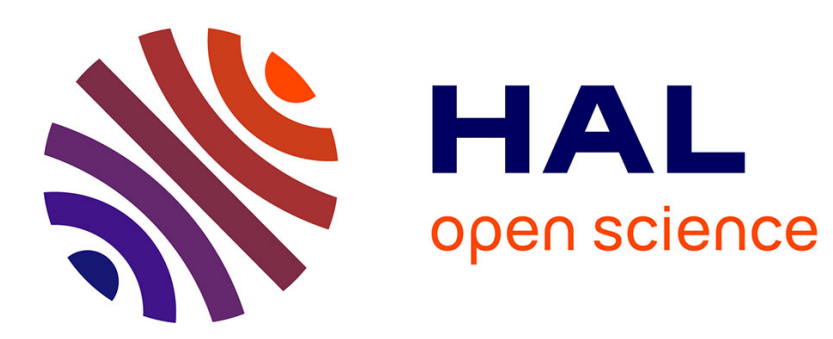

\title{
Firms as Bundles of Discrete Resources - Towards an Explanation of the Exponential Distribution of Firm Growth Rates
}

\author{
Alex Coad
}

\section{- To cite this version:}

Alex Coad. Firms as Bundles of Discrete Resources - Towards an Explanation of the Exponential Distribution of Firm Growth Rates. 2008. halshs-00331282

\section{HAL Id: halshs-00331282 \\ https://shs.hal.science/halshs-00331282}

Submitted on 16 Oct 2008

HAL is a multi-disciplinary open access archive for the deposit and dissemination of scientific research documents, whether they are published or not. The documents may come from teaching and research institutions in France or abroad, or from public or private research centers.
L'archive ouverte pluridisciplinaire HAL, est destinée au dépôt et à la diffusion de documents scientifiques de niveau recherche, publiés ou non, émanant des établissements d'enseignement et de recherche français ou étrangers, des laboratoires publics ou privés. 


\section{Documents de Travail du Centre d'Economie de la Sorbonne}
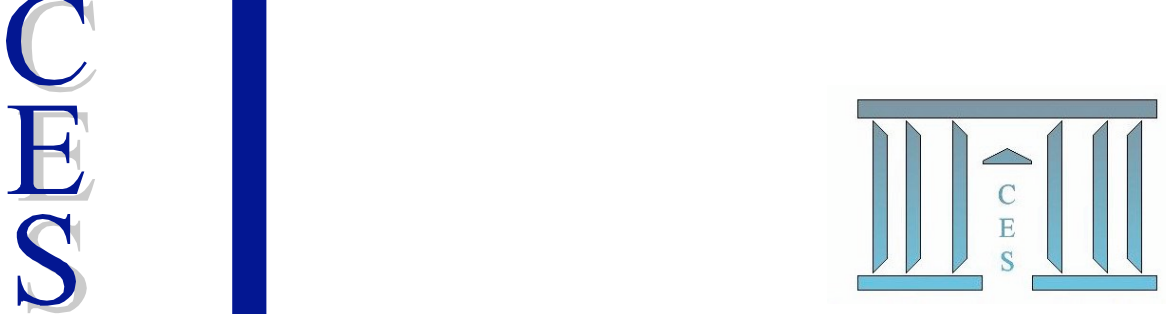

Firms as Bundles of Discrete Resources - Towards an Explanation of the Exponential Distribution of Firm Growth Rates

Alex COAD

2008.55 


\title{
Firms as Bundles of Discrete Resources - Towards an Explanation of the Exponential Distribution of Firm Growth Rates*
}

\author{
Alex Coad ${ }^{a b \dagger}$ \\ a Max Planck Institute of Economics, Jena, Germany \\ $b$ Centre d'Economie de la Sorbonne, Equipe MATISSE, Univ. Paris 1 - CNRS
}

\begin{abstract}
A robust feature of the corporate growth process is the Laplace, or symmetric exponential, distribution of firm growth rates. In this paper, we sketch out a class of simple theoretical models capable of explaining this empirical regularity. We do not attempt to generalize on where growth opportunities come from, but rather we focus on how firms build upon growth opportunities. We borrow ideas from the self-organizing criticality literature to explain how the interdependent nature of discrete resources may lead to the triggering off of a series of additions to a firm's resources. In a first formal model we consider the case of employment growth in a hierarchy, and observe that growth rates follow an exponential distribution. In a second model we include plant and capital as resources and we are able to reproduce a number of stylized facts about firm growth.

A LA RECHERCHE D'UNE EXPLICATION DE LA DISTRIBUTION EXPONENTIELLE DES TAUX DE CROISSANCE DES FIRMES

Résumé: Les taux de croissance des firmes sont généralement distribués selon une loi exponentielle. Cette régularité empirique a été vérifiée pour plusieurs bases de données et à plusieurs niveaux d'agrégation. Dans ce papier, nous proposons un modèle théorique simple qui est capable de reproduire cette distribution exponentielle. Nous ne tentons aucune généralisation relative aux causes d'apparition des opportunités de croissance, mais nous nous attachons plutôt au comment les firmes réagissent et internalisent ces opportunités. Nous utilisons des concepts issus de la
\end{abstract}

*Thanks go to Giulio Bottazzi, David Brée, Thomas Brenner, Mike Dietrich, Giovanni Dosi, Davide Fiaschi, Ricardo Mamede, Luigi Marengo, Rosanna Nisticò, Bernard Paulré, Rekha Rao, Giorgio Ricchiuti, Angelo Secchi, Ulrich Witt and participants at the 'Economic Evolution as a Learning Process' course at the Max Planck Institute, Jena, Germany, March 13-24 2006; the workshop on 'Internal Organisation, Cooperative Relationships among Firms and Competitiveness' in Lucca, January 2007; and the Econophysics conference in Ancona, September 27-29, 2007. Zlata Jakubovic provided excellent research assistance. The usual caveat applies.

${ }^{\dagger}$ Corresponding Author: Alex Coad, Max Planck Institute of Economics, Evolutionary Economics Group, Kahlaische Strasse 10, D-07745 Jena, Germany. Phone: +49 3641 686822. Fax: +49 3641 686868. E-mail: coad@econ.mpg.de 
littérature sur la 'criticité' auto-organisatrice pour expliquer comment la nature interdépendante de ressources discrètes peut déclencher toute une série d'additions aux ressources d'une firme. Dans un premier modèle, nous considérons le cas de la croissance en termes d'emploi dans le contexte d'une hiérarchie, et nous observons que les taux de croissance suivent une loi exponentielle. Dans un deuxième modèle, nous incluons les établissements et les machines comme ressources, et le modèle est capable de reproduire plusieurs faits stylisés sur la croissance des firmes.

JEL codes: L1, C1

Keywords: Firm growth rates, Exponential distribution, Hierarchy, Growth autocorrelation

Mots clés: Croissance des firmes, distribution exponentielle, hiérarchie 


\section{Introduction}

It has long been known that the distribution of firm growth rates is fat-tailed. In an early contribution, Ashton (1926) considers the growth patterns of British textile firms and observes that: "In their growth they obey no one law. A few apparently undergo a steady expansion... With others, increase in size takes place by a sudden leap..." (Ashton (1926) pp. 572-573). Little dedicates a section of his 1962 empirical study to the distribution of growth rates, and also finds that the distribution is fat-tailed. However, he concludes the section without proposing any theoretical explanation: "I do not know what plausible hypothesis explains the highly leptokurtic nature of the distributions" (Little (1962) p. 408). Recent empirical research into industrial dynamics has discovered that the distribution of firm growth rates closely follows the Laplace distribution, also known as the symmetric exponential distribution. Using the Compustat database of US manufacturing firms, Stanley et al. (1996) and Amaral et al. (1997) observe a 'tent-shaped' distribution characterized by a straight line on logarithmic plots that corresponds to the Laplace density. The Laplace distribution is also found to be a rather useful heuristic when considering growth rates of firms in the worldwide pharmaceutical industry (Bottazzi et al. (2001). Giulio Bottazzi and coauthors extend these findings by considering the Laplace density in the wider context of the family of Subbotin distributions. They find that, for the Compustat database, the Laplace is indeed a suitable distribution for modelling firm growth rates, at both aggregate and disaggregated levels of analysis (Bottazzi and Secchi (2003a)). The Laplacian nature of the distribution of growth rates also holds for other databases, such as Italian manufacturing (Bottazzi et al. (2007)). ${ }^{1}$ In addition, the Laplace distribution appears to hold across a variety of firm growth indicators, such as Sales growth, employment growth or Value Added growth (Bottazzi et al. (2007)). The growth rates of French manufacturing firms have also been studied, and roughly speaking a similar shape was observed, although it must be said that the empirical density was noticeably fatter-tailed than the Laplace (Bottazzi et al. (2008)). ${ }^{2}$ In Figure 1, we use the Compustat database to show the heavy-tailed distribution of annual employment growth rates for large US firms.

In this paper, we argue that it would be fruitful to conceive firms as being composed of discrete, interrelated resources, that are subject to local interactions, and susceptible to containing some degree of organizational slack. We sketch out two similar theoretical models that rely on these characteristics of firms to explain a number of 'stylized facts' of firm growth.

\footnotetext{
${ }^{1}$ Reichstein and Jensen (2005) investigate the growth rate distribution of Danish firms, and, unlike most previous work, they observe asymmetries in the growth rate distribution, such that the Laplace is a better fit to the upper tail than the lower tail of the growth rate distribution.

2 i.e. the observed subbotin $b$ parameter (the 'shape' parameter) is significantly lower than the Laplace value of 1. This highlights the importance of following Bottazzi et al. (2002) and considering the Laplace as a special case in the Subbotin family of distributions.
} 

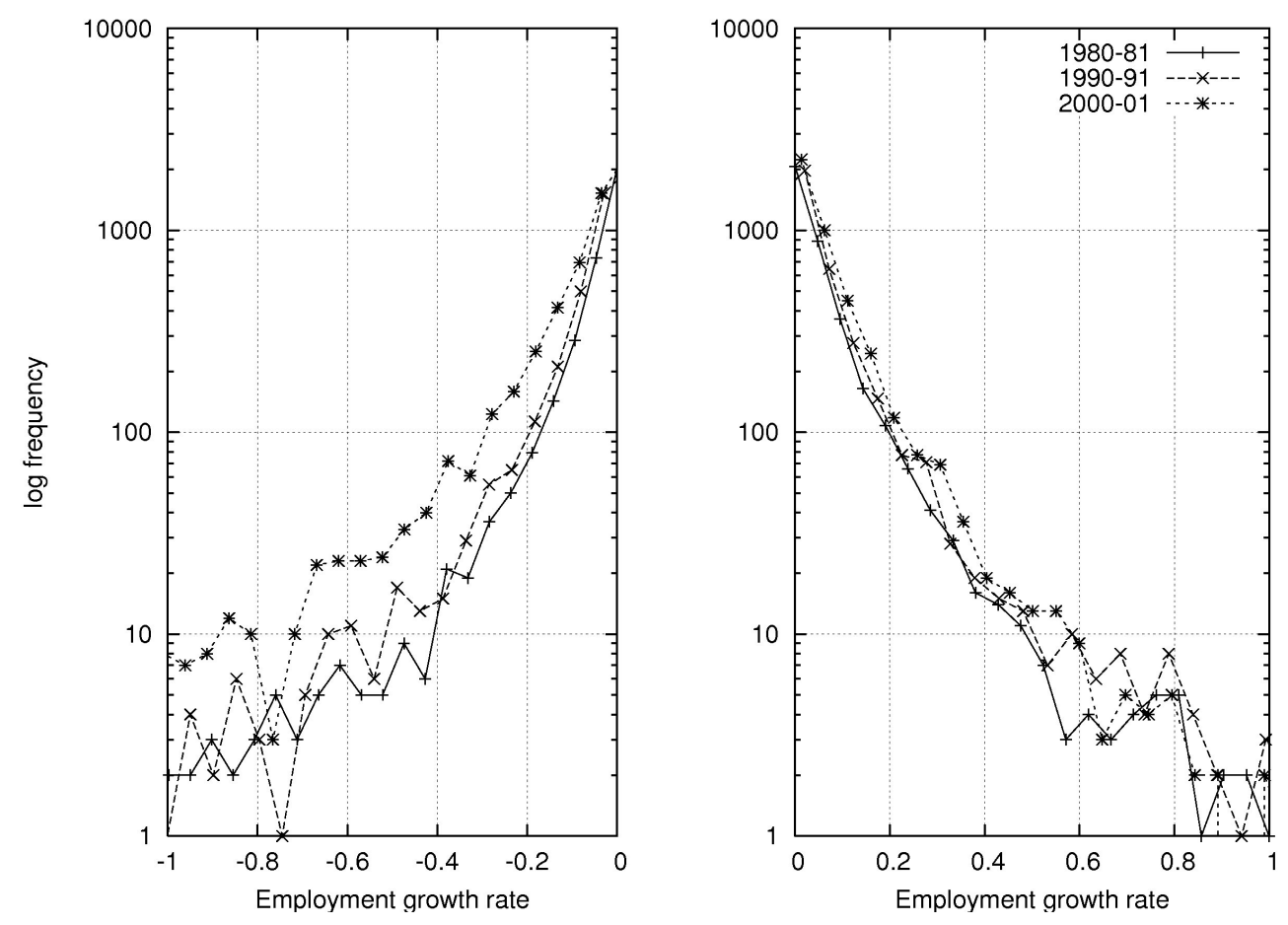

Figure 1: The empirical distribution of employment growth rates, elaborated by the author using the Compustat dataset for large US firms. Note the log scale on the $y$-axis. Employment growth is calculated in the usual way of taking log-differences of total employment in successive periods. Annual employment growth rates are calculated for the periods 1980-81, 1990-91 and 2000-01, obtaining 5256, 5931 and 7948 observations respectively. For each period, firms are sorted into 100 bins.

In section 2 we review and discuss previous models of industry growth. Section 3 contains a discussion whereby we identify some features common to firms - i.e. firms can be seen as composed of lumpy, indivisible resources that are subject to non-linear interactions. In Section 4 we present a simple model of employment growth in a hierarchical organization. Section 5 contains a model that is computationally rather complex, the properties of which we explore using simulation analysis. Section 6 concludes.

\section{A Discussion of Previous Models}

There is something of a tradition in Industrial Organization modelling to represent growth processes in purely stochastic terms. Ijiri and Simon (1977) offered an explanation of the skewed firm size distribution in terms of a random process in which the probability of a firm taking up an additional business opportunity is conditional upon its size. This model, dubbed the 'island' model because of the independent arrival of the growth opportunities, has been widely accepted, and interest in it was recently revived by Sutton (1998).

Previous models that focused on the exponential distribution of firm growth rates have also 
taken the approach of stochastic explanations. Amaral et al. (1997) develop a model in which the emergence of the distribution rests on a particular specification of the functional form of the stochastic growth process. However, there is little justification of the choice of such a functional form, and so their model appears to be more of a tautology than an explanation. The model in Bottazzi and Secchi (2003b) and Bottazzi and Secchi (2006a) also conceives of firm growth as a random process - "in our model luck is the principal factor that finally distinguishes winners from losers among the contenders" (Bottazzi and Secchi (2006a)). The allocation of growth opportunities is governed by the 'Polya Urn' statistics, and as a justification of such mathematical apparatus they evoke the principle of 'increasing returns to growth' in the competitive process (more in the sense of Arthur (1989) rather than in that of the KaldorVerdoorn 'dynamic increasing returns'). Within the period of a calendar year, they suppose that the probability of a growth opportunity being taken up depends positively on the number of growth opportunities already taken up that year. This hypothesis, however, is difficult to reconcile with the existence of a small negative year-on-year autocorrelation of growth rates observed in many empirical studies. ${ }^{3}$ Furthermore, given that the resulting distribution is determined by the choice of the underlying stochastic process, there are limits to how much such models can actually 'explain'.

The choice of stochastic models to describe industrial evolution bears witness to a reluctance to generalize across firms. Firms grow for a wide variety of different reasons, they are indeed heterogeneous, and it is believed that the best or only way to model growth may be by treating it as purely stochastic. To move beyond describing industry dynamics in terms of purely random shocks, we need to address the following question: "Can we generalize across firms?" Our answer is: "Yes we can, to some degree".

Without denying the complexity of commercial organizations or the heterogeneity that exists between firms from different sectors of the economy, we maintain that there are some general features that are present in firms. (Indeed, Simon (1962) suggests that there are some broad features that appear to be common not only to all firms but to all complex systems!) The theoretical explanation proposed here is rooted in the 'resource-based approach', which views firms as being composed of discrete, complementary resources (Penrose (1959)). In addition, we allow for the possibility of growth being accommodated by organizational slack. Organizational slack is a widely-recognized characteristic of business firms - indeed, a firm's resources will not be fully utilized at any given time for a number of reasons. ${ }^{4}$ However,

\footnotetext{
${ }^{3}$ For a detailed survey of growth rate autocorrelation, see Coad (2007).

${ }^{4}$ Here are a few possible examples. Slack may be present because indivisibilities of key inputs may prevent a firm from attaining perfect productive efficiency. Also, slack may creep in as the learning-by-doing effects that increase a worker's productivity are not counterbalanced by increasing demands made of the worker. Furthermore, slack may be necessary because firms must be able to adapt and act flexibly in response to unforeseen contingencies and the changing market environment.
} 
managers will seek to use a firm's resources efficiently, to have them as close as possible to 'full utilization'. If a firm's resources are under-utilized, then growth can feed off these slack resources. ${ }^{5}$ On the other hand, if resources are already more or less fully employed, then growth will only be possible with the addition of new resources. In the former case, growth requires no additional investment, whilst in the latter case, firm growth will be accompanied by potentially wide-scale investment. ${ }^{6}$ This depiction of firm growth can be expressed in terms of self-organizing criticality. The firm can be seen as a system which tends to a "critical state' of full utilization of its resources, as managers strive to organize the firms resources efficiently within the firm's hierarchical framework. Depending upon the criticality of the system, the addition of an activity during growth will result in a (marginally) increased strain for many associated resources, thus potentially triggering off a chain reaction of subsequent growth across the whole of the organization. In this vein, Dixon comments on the criticality of a firm at a more general level: "the later addition of one person to regular activities can bring into operation a chain of reactions in the form of salaried employee increases, salary increases, and fixed asset additions" (Dixon, 1953, p. 50). Similarly, Hannan writes: "changes in one organizational feature often generate cascades of additional changes, because of the interdependence among parts of an organization" (Hannan, 2005, p. 61). Weick and Quinn put it this way: "Small changes can be decisive if they occur on the edge of chaos... in interconnected systems, there is no such thing as marginal change" (Weick and Quinn, 1999, p. 378). The 'avalanche' will only stop if there is sufficient slack capacity to absorb the extra workload associated with the additional resources.

To illustrate this idea, we propose models that are capable of generating heavy-tailed growth rate distributions within the time series of a single firm. In Section 4 we consider the special case of the propagation of employment growth throughout the various levels of a firm's hierarchy. The organization of production in a hierarchy is indeed a general feature of all firms - in fact, in the Transaction-Cost-Economics literature, the words 'firm' and 'hierarchy' are used almost interchangeably. In this context, a firm may grow by adding an additional worker on the factory shopfloor, who will require the attention of a supervisor. It may occur, however, that all of the current supervisors are already too busy to take on this extra burden of supervision. With a small probability, then, the addition of this supplementary worker requires that the firm hire another supervisor. Furthermore, the addition of a supervisor may

\footnotetext{
${ }^{5}$ Penrose writes "[a]t all times there exist, within every firm, pools of unused productive services and these, together with the changing knowledge of management, create a productive opportunity which is unique for each firm." (Penrose, 1960, p. 2). Similarly, Lesourne writes "L'entreprise cherchera à employer ces ressources inutilisées, mais en le faisant en créera d'autres, en ne réussissant jamais à atteindre un état d'équilibre complet dans l'utilisation de ses resources" (Lesourne, 1973, p. 92).

${ }^{6}$ A similar story could be imagined for growth after the arrival of an innovation, since the innovating firm will typically have to invest in a wide range of complementary assets in order to profit from the innovation (Teece (1986), see also Coad and Rao (2008)).
} 
then increase the administrative workload of the central office, such that this latter also needs to hire a supplementary worker. An analogy with the classic 'sandpile' model ${ }^{7}$ can therefore be drawn, as the addition of a supplementary worker can lead to a 'snowball effect' of hiring of employees at higher levels of the hierarchy. We expand upon this model in Section 5, so that our model consists not only of labour but also capital inputs.

\section{Theoretical Foundations}

The path-breaking book of Penrose (1959) is a milestone for research into the theory of the firm. In this book, Penrose explains that firms are composed of 'resources' which are idiosyncratic assets that are essential inputs into the productive process. Although Penrose's book is mainly concerned with human resources (in particular, the scarce resource that is managerial talent), other authors have identified other examples of resources. Brand names, in-house knowledge of technology, employment of skilled personnel, trade contracts, machinery, and efficient procedures are other such examples (Wernerfelt (1984)). Montgomery (1994) suggests that Disney's cast of animated characters can be viewed as a resouce, that has been observed to fuel diversification. Somewhat more unusual is the affirmation that even emotions such as anger and frustration can be considered to be organization-specific 'resources' (Feldman, 2004, p. 304). Furthermore, Winter (1995) comments on the similarity of the Penrosian concept of 'resources' and the evolutionary notion of 'organizational routines' and concludes that even routines can be considered as resources. ${ }^{8}$

Proposition 1 Firms can be seen as being composed of resources

One of the major features of these resources is their indivisible nature. This was described quite clearly by Penrose and has been recognized by many subsequent scholars. To summarize, Garnsey writes "Penrose pointed out that many of the resources required for expansion are only available in multiples that do not match up, as where new equipment creates excess capacity. This creates incentives to exploit unused resources through further growth." (Garnsey, 1998, p. 539).

\section{Proposition 2 These resources are discrete and indivisible}

\footnotetext{
${ }^{7}$ See Bak and Chen (1991); see also Bak et al. (1993) for an economic application. In the 'sandpile' model, grains of sand are dropped on top of each other until a sandpile is formed. "[R]andomly dropping on additional sand will result in the slope of the pile increasing to a critical slope, at which point avalanches of all sizes (limited only by the size of the pile) can occur in response to the dropping of a single additional grain of sand." (Bak et al. (1993) p. 7).

${ }^{8}$ Winter writes "routines clearly qualify as resources, given the expansive use of the term 'resources' in the literature of the resource-based view. ... a routine in operation at a particular site can be conceived as a web of coordinating relationships connecting specific resources..." (Winter, 1995, pp. 148-149).
} 
The indivisible resources that form the basis for a firm's productive potential are not perfect substitutes but they need to be combined in roughly constant proportions in order for the firm to produce its output. As a consequence, firms strive to find those combinations of resources that reduce slack. Penrose describes this idea in these words: "[i]f a collection of indivisible productive resources is to be fully used, the minimum level of output at which the firm must produce must correspond to the least common multiple of the various maximum outputs obtainable from the smallest unit in which each type of resource can be acquired." (Penrose, 1959, p. 68). It follows that "[u]nused productive services are, for the enterprising firm, at the same time a challenge to innovate [and] an incentive to expand ..." (Penrose, 1959, p. 85). In other words, the resources in a firm are interdependent because, under circumstances where firms strive for the most efficient combination of resources, the addition of one indivisible resource may well have consequences on the desirable levels of other resources.

Proposition 3 These resources are interdependent and subject to local interactions. This may lead to non-linearities as firms add indivisible resources to arrive at an efficient level of production.

\section{A Simplified Model}

\subsection{Intuition of the model}

In the previous discussion, we argued that firms grow by adding discrete resources to a complex of interdependent resources that they already possess. However, a verbal discussion is not methodologically sufficient to prove our point that discrete, interdependent resources organized within a firm bring about a Laplace distribution of growth rates. In this section, therefore, we present an analytical model capable of reproducing the observed functional form by exploiting a few simplifying assumptions. Our attempts to construct a formal model, it would appear, receive the blessing of those who are concerned that the modelling of heavy-tailed phenomena has received insufficient attention in the literature (McKelvey and Andriani (2005)).

We characterize a firm as being composed of a relatively large number of hierarchies. ${ }^{9}$ The bottom layer of the firm (i.e. the very lowest hierarchical level) is composed exclusively of productive workers, whilst all of the other levels are composed of managers whose task is to supervise either productive workers or subordinate managers (see Figure 2 for an illustration). A firm grows by adding a productive worker. The number of managers is determined by the

\footnotetext{
${ }^{9}$ We do not need to define the number 'large' nor define what happens at the very top of the hierarchy. Also, we do not need to suppose that the number of hierarchies tends to infinity, because we only want to explain the distribution of growth rates for a certain limited range. An implication of this assumption is that this model is not suitable for describing growth processes in very small firms.
} 

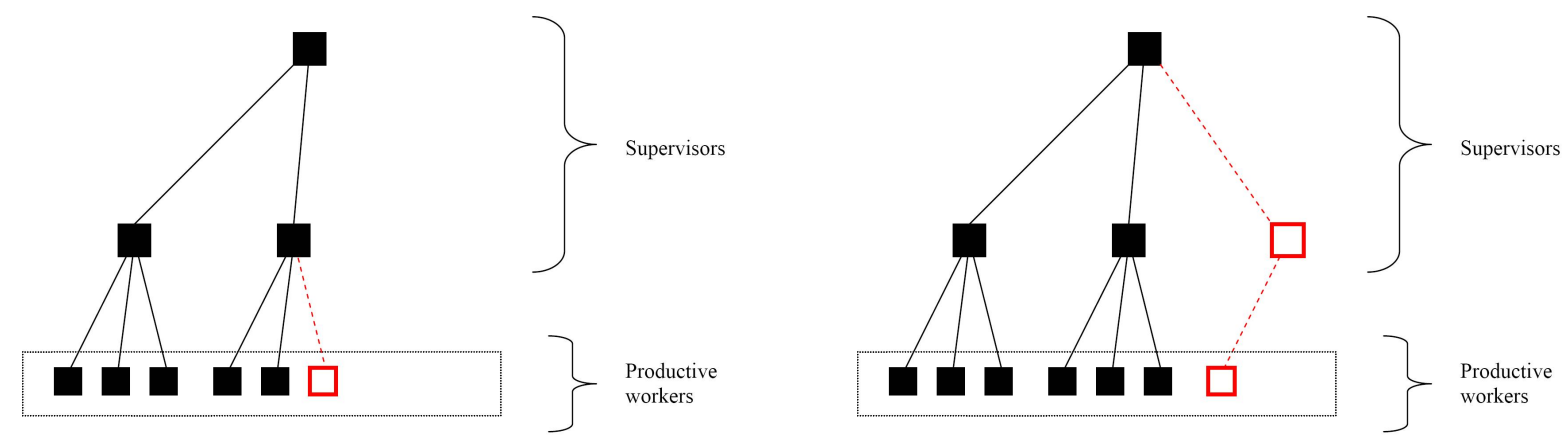

Figure 2: An illustration of the underlying intuition of the model, where the span of control is $\alpha=3$. Depending upon the 'criticality' of the system, the addition of a productive worker may lead to an increase in the number of supervisors further up the hierarchy. If there is some slack in the system, a productive worker can be added and new supervisors need not be added (see left). If, however, the attention of supervisors is already at full utilization, the addition of a productive worker will require the addition of a supervisor (see right).

number of productive workers and also by limits on the efficient span of control, $\alpha$, which correspond to the maximum number of subordinates that a manager can effectively supervise. "At executive levels [the span of control] is seldom less than three, and seldom more than ten, and usually lies within narrower bounds - particularly if we take averages over all executives in an organization at a given level." (Simon, 1957, p. 32). In this model, though, we do not need to attribute any specific numerical value to $\alpha$ and so we leave it in algebraic form. It is computationally helpful, and also theoretically meaningful, however, to assume that $\alpha$ is a whole number that is strictly greater than unity (i.e. $\alpha \in \mathbb{N}^{+}, \alpha>1$ ). For analytical simplicity, we assume that $\alpha$ is a constant and does not vary either within a hierarchical level or across levels (for a discussion of the plausibility of this assumption, see Williamson (1967) p. 128). For the purposes of this model, we also must assume that adjustment of the firm's hierarchical organization to additional productive workers occurs within one time period. Finally, we assume that the firm is initially at a stable state, such that it is already efficiently organized in the sense that it is not possible for it to employ fewer managers given the number of productive workers and its given value of $\alpha$ (i.e. the limit on the efficient span of control). The reader may notice major similarities between the model developed here and the executive compensation model of Simon (1957) and the information flows model of Williamson (1967). The fact that the same hierarchical model has been applied in quite different contexts lends credibility to its use here - indeed, we cannot be accused of having conclusions that emerge from ad hoc modelling assumptions.

A summary understanding can be obtained by looking at Figure 2. Two important points should be emphasized. First, there is a distinction between total production $n$ and total employment $x$. Total production corresponds to the number of productive workers, i.e. $n$, 
while total employment corresponds to the number of both productive workers and supervisors combined, i.e. $x$. Second, it should be noted that we do not attempt to generalize on the sources of growth opportunities, but rather we focus on how firms build upon given growth opportunities. ${ }^{10}$ We argue that the fat-tailed distribution of growth rates does not come from the distribution of opportunities available to firms, but rather on the reactions of firms to growth stimuli. The model is admittedly a gross simplification and does not take into account such factors as the interdependence of growth rates between firms, flexibility of $\alpha$ (the span of control parameter), liquidity constraints that limit growth, or limits on the availability of suitable workers. Nonetheless, its simplicity will make it clear to what properties we owe the emergence of the distribution.

\subsection{Formal model}

Let us begin with the simplest possible case, considering one firm that grows by adding just one productive worker (i.e. $\Delta n=1$ ). If new productive workers can be integrated without having to add a supervisor, we have $\Delta n=\Delta x$; i.e. the number of productive workers added is equal to change in total employment. It is possible, however, that all of the managers in the second hierarchical level (i.e. those that supervise the productive workers) are already fully occupied. This will occur when the number of productive workers (before adding the new one) is exactly a multiple of $\alpha$. If this is the case, the arrival of the supplementary worker will require that one supplementary manager be hired at the next hierarchical level. This scenario will occur with probability $1 / \alpha$. However, the arrival of this new manager at the second level may add to the workload of managers on the third hierarchical level, and so on. The probability that the addition of a productive worker leads to at least two managers being hired at two successive levels is $1 / \alpha \times 1 / \alpha=1 / \alpha^{2}$. We can continue with this reasoning to end up with the following distribution of employment growth:

$$
\begin{aligned}
& \text { Prob. }(\Delta x \geq 1 \mid \Delta n=1)=1 \\
& \text { Prob. }(\Delta x \geq 2 \mid \Delta n=1)=1 / \alpha \\
& \text { Prob. }(\Delta x \geq 3 \mid \Delta n=1)=1 / \alpha^{2} \\
& \text {.. }
\end{aligned}
$$

and so on. Formally, we have an exponential distribution with the following functional form:

$$
P(\Delta x \geq \gamma \mid \Delta n=1)=\alpha^{1-\gamma}
$$

\footnotetext{
${ }^{10}$ Our model is thus in line with the previous theoretical models of industrial structure and dynamics reviewed in Section 2, where growth opportunities are supposed to arrive by themselves and little attention is paid to their source.
} 

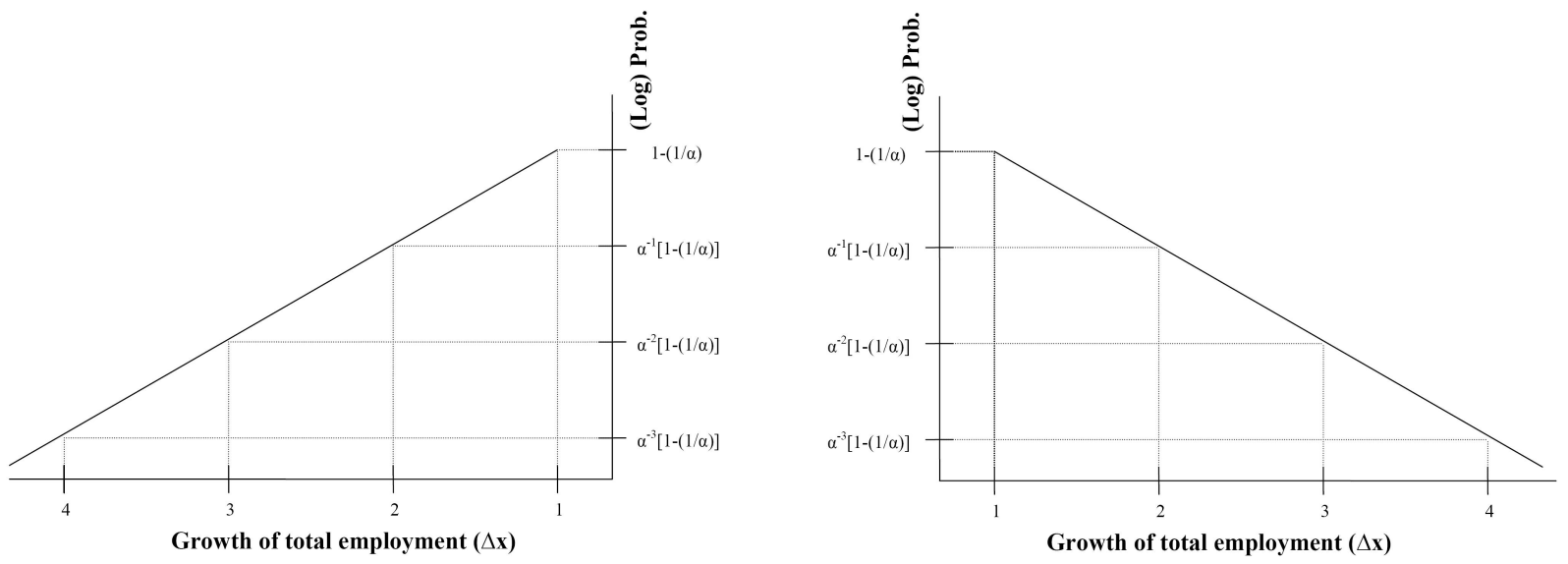

Figure 3: The distribution of growth of total employment if a firm grows by $\Delta n=1$ (right figure, see Result 1), or if a firm shrinks by $\Delta n=1$ (left figure, see Result 2).

or, expressed differently,

$$
P(\Delta x=\gamma \mid \Delta n=1)=\alpha^{1-\gamma}(1-1 / \alpha)
$$

where $\gamma$ is a positive integer $(\gamma \geq \Delta n)$. We therefore observe that the distribution of total employment growth $(\Delta x)$ of a firm that grows by adding one productive worker will follow an exponential distribution.

It is also possible to generalize for the case where a firm grows by adding $\Delta n \in \mathbb{N}^{+}$ productive workers (with, of course, $\Delta x \geq \Delta n$ ). For $\Delta n<\alpha$, we obtain the following distribution:

$$
\begin{aligned}
& P(\Delta x=\gamma \mid \Delta n)=1-\Delta n / \alpha \quad \text { if } \quad \gamma=\Delta n \\
& P(\Delta x=\gamma \mid \Delta n)=\Delta n \cdot \alpha^{\Delta n-\gamma}(1-1 / \alpha) \quad \text { if } \quad \gamma>\Delta n
\end{aligned}
$$

where equation (2) corresponds to the special case where $\Delta n=1$.

Thus, we have:

Result 1 The distribution of growth of total employment of a firm that adds $\Delta n$ productive workers will follow an exponential distribution.

An illustration is offered in Figure 3 (right).

Analogical reasoning can be applied to the case where a firm shrinks in size. Consider a firm that shrinks by $\Delta n$ units - at least one supervisor will no longer be needed when, after shrinking, the number of productive workers is an exact multiple of $\alpha$. Formally, we can still use Equation (3), where a firm shrinks by $\Delta x$ employees as a response to shedding $\Delta n$ production workers (with $\Delta n<\alpha$ ), i.e.: 


$$
\begin{array}{llll}
P(\Delta x=\gamma \mid \Delta n) & =1-\Delta n / \alpha & \text { if } & \Delta x=\Delta n \\
P(\Delta x=\gamma \mid \Delta n) & =\Delta n \cdot \alpha^{\Delta n-\gamma}(1-1 / \alpha) & \text { if } & \Delta x>\Delta n
\end{array}
$$

Result 2 The distribution of growth of total employment of a firm that shrinks by $\Delta n$ productive workers will follow an exponential distribution.

An illustration is given in Figure 3 (left).

Autocorrelation dynamics It is also possible to derive the conditional autocorrelation dynamics of the firm's growth dynamics. Consider the case where one production worker is added in each period $t$, i.e. $n_{t}=n_{t-1}+1$. The conditional growth autocorrelation can be written as:

$$
\begin{aligned}
& P\left(x_{t}-x_{t-1}>1 \mid x_{t-1}-x_{t-2}>1\right)=0 \\
& P\left(x_{t}-x_{t-1}>1 \mid x_{t-1}-x_{t-2}=1\right)=\frac{1}{\alpha-1}
\end{aligned}
$$

If the firm experienced a growth spurt in the previous period (i.e. $x_{t-1}-x_{t-2}>1$ ), it has a probability of zero of repeating this growth performance in the following period. If, however, the firm added a productive worker in the previous period but this did not trigger off the addition of a supervisor, then the addition of a productive worker in this period has a positive probability of leading to the further addition of a supervisor.

Given that $E\left(x_{t}-x_{t-1} \mid x_{t-1}-x_{t-2}>1\right)=1$ and $E\left(x_{t}-x_{t-1} \mid x_{t-1}-x_{t-2}=1\right)>1$, we observe negative growth autocorrelation in the case where a growth spurt of $x$ was triggered in the previous period (i.e. when $x_{t-1}-x_{t-2}>1$ ).

We will pursue our analysis of conditional autocorrelation profiles in Section 5.3.

\subsection{Discussion}

The model is admittedly far too simple to be realistic, yet it's simplicity makes for greater visibility of the source of the emergence of the symmetric exponential distribution. The model can be seen as the simplest model in a family of possible models that view firms as coherent collections of resources that are complementary and discrete. These latter are subject to localised interactions and embedded in an organization that tends to a critical state of full utilization of its resources. In this context, a small growth stimulus working through local interaction channels can be transmitted throughout a firm to produce potentially large-scale 
effects. We argue that it is these properties that explain the emergence of the observed fattailed growth rate distributions.

The model describes the dynamics of a single, 'autistic' organization and makes no attempt to account for competitive interactions between firms. In our view, this is not a serious flaw. Other explanations of the fat-tailed growth rate distribution have emphasized the complex nature of inter-firm competition as the source of the emergence of the observed distribution (e.g. Bottazzi and Secchi (2006a), McKelvey and Andriani (2005)). Recent empirical work has nonetheless cast doubt on the importance of inter-firm competition as a factor conditioning firm growth rates. Sutton (2007) analyzes the dynamics of market shares of the largest and second largest firms in a number of Japanese industries, and finds (perhaps surprisingly) that their market share dynamics can be modeled as statistically independent. Only in the case where the combined market share of an industry's two largest firms is at least $90 \%$ of the industry total does inter-firm competition leave a detectable statistical footprint. Geroski and Gugler (2004) consider the impact of the growth of rival firms on a firm's employment growth, using a database on several thousand of the largest firms in 14 European countries. Rival firms are defined as other firms in the same 3-digit industry. In their main regression results (their Table 2) they are unable to detect any significant effect of rival's growth on firm growth, although they do find a significant negative effect in specific industries (i.e. differentiated good industries and advertising intensive industries). In our model, it is the complex nature of interactions between the resources within a firm, rather than the competitive struggle between firms, that accounts for the emergence of the observed growth rates distribution.

Some caveats of the model should nonetheless be mentioned. First, the model only considers the case of employment growth and does not consider other aspects of firm growth (such as growth of sales or growth of fixed capital). Second, all of the interactions take place in a vertical direction (up or down the hierarchical channels) rather than in a horizontal direction. The model therefore places strict limits on the nature of interactions that is probably not a realistic portrayal of how a firm's resources interact. Third, the addition of an extra production worker at the bottom of the hierarchy is assumed to lead to a modification of total employment that is, if anything, instantaneous. This might not be an accurate assumption, however, considering that: "[t]here is a considerable time lag between the growth of numbers of production workers and the expansion in employment of other personnel" (McGuire, quoted in Starbuck (1971) p. 54). Fourth, the model is very simple - this is both an advantage and a disadvantage. Such as simple model cannot be an accurate portrayal of firm growth. 


\section{$5 \quad$ Extending the Model}

The previous model had many limitations, as we have already discussed. In an attempt to improve the model, we now try to develop it into something more realistic by introducing capital as a factor of production. Whereas the previous model consisted of productive workers and supervisors, here we include in an analogous fashion machines and production plants, with the restriction that each production plant can house a limited number of machines. We also introduce a further input which serves as a 'numeraire', which combines productive labour and machines in order to produce the final good. For the sake of simplicity, we do not allow for any substitution between labour and capital in the production of the final good, although this could be relaxed in further work.

The following model serves as a useful illustration of the growth mechanism. Due to difficulties in applying optimization algorithms to cases involving integer restrictions, however, we are prevented from firmly establishing the sensitivity of the model to different parameter settings. As such, the model is at a preliminary stage and should be seen primarily as an aid to intuition.

\subsection{Introducing the Model}

Consider a firm's production $Q$ that is produced from $N$ inputs in the following way:

$$
Q=f(A, B, \ldots, N)
$$

Equation (6) implies that production of final goods requires many inputs. These inputs are lumpy and indivisible. In reality, there are many such indivisible inputs to a production process, In the present model, however, we limit ourselves to the five inputs mentioned above. In this example we envisage that $A$ corresponds to the basic raw materials required for a 'production run', $B$ to the number of production employees, $C$ to the number of 'machines', $D$ to the number of supervisors (non-production workers), and $E$ to the number of production plants. It is also meaningful to restrict the values of these inputs to integer number values, i.e. $(A, B, C, D, E) \in \mathbb{N}^{+}$.

The production function has the following functional form:

$$
\begin{aligned}
Q & =f(A, B, C, D, E) \\
& =\operatorname{Min}\left(A, B \operatorname{DIV} r^{B}, C \operatorname{DIV} r^{C}, D \operatorname{DIV} r^{D}, E \operatorname{DIV} r^{E}\right)
\end{aligned}
$$


where $\operatorname{Min}($.$) is the function that selects the minimum from the list of values in parentheses.$ The DIV operator corresponds to integer division, whereby the result is integer and any remainder is discarded. ${ }^{11}$ Integer division effectively helps us to model the indivisible nature of the inputs.

The $r^{B}$ coefficient (with $r^{B}<1$ ) corresponds to the requirements of input $\mathrm{B}$ into the production process. Strictly speaking, $r^{B}$ corresponds to the number of units of $B$ required for one unit of $\mathrm{A}$. In other words, a production run requires not only raw materials but also the labour services of an employee. Analogous interpretations exist for the $r^{C}, r^{D}$, and $r^{E}$ coefficients.

Using a similar reasoning to that developed in Section 4, it follows that the addition of one more production run has an (unconditional) probability of $r^{B}$ of resulting in the addition of a production worker, as well as an (unconditional) probability of $r^{C}$ of resulting in the addition of a machine. In turn, any additional employee may lead to the addition of a supervisor, and any extra machine may lead to the construction of a new production plant.

It is thus apparent that the marginal costs of adding one more production run depend upon the 'criticality' of the system. In some cases, there is enough 'slack' to accommodate the production run without any repercussions. In other cases, adding a production run results in cascading investments throughout the organization. In what follows, we will observe how profit-maximizing firms decide whether or not to satisfy marginal changes in demand with additional production runs, depending upon the 'criticality' of the organization of the firm's productive inputs. As such, the firm's marginal cost depends upon the criticality of the system.

A firm's cost function can be written as:

$$
C O S T=g(A, B, C, D, E)=\left(c^{A} A+c^{B} B+c^{C} C+c^{D} D+c^{E} E\right)
$$

Where $c^{A}$ is the cost to the firm of input $A$, and where analogous definitions hold for $c^{B}$, $c^{C}, c^{D}$, and $c^{E}$.

For analytical convenience we make the usual assumption that firms seek to maximize profits:

$$
\max _{Q} P \cdot Q-C O S T
$$

subject to given demand conditions. For simplicity, we consider a downward-sloping demand curve which corresponds to the case of imperfect competition: ${ }^{12}$

\footnotetext{
${ }^{11}$ In other words, the result of $B$ DIV $r^{B}$ is the integer obtained when $B$ is divided by $r^{B}$ and any remainder is thrown away. For example, 7 DIV 2 is the integer 3.

${ }^{12}$ If we assume that the conditions of demand are those of perfect competition (i.e. that price is given) then firms face no scale effects and the model in its present form does not rule out infinite increases in size. In this case, it would thus be necessary to impose some restriction which prevents the apparition of cases in
} 


$$
P=h(Q)=\beta-\phi Q
$$

where $\beta$ and $\phi$ are parameters.

\subsection{A quantitative example}

In this section we will consider the case with five inputs: $A, B, C, D$ and $E$.

Substituting (10), (7) and (8) into (9), we obtain:

$$
\max _{A, B, C, D, E}\left\{\begin{array}{l}
\beta \cdot \operatorname{Min}\left(A, B \operatorname{DIV} r^{B}, C \operatorname{DIV} r^{C}, D \text { DIV } r^{D}, E \text { DIV } r^{E}\right) \\
-\phi \cdot \operatorname{Min}\left(A, B \operatorname{DIV} r^{B}, C \operatorname{DIV} r^{C}, D \text { DIV } r^{D}, E \operatorname{DIV} r^{E}\right)^{2} \\
-\left(c^{A} A+c^{B} B+c^{C} C+c^{D} D+c^{E} E\right)
\end{array}\right\}
$$

This problem is obviously too complex to solve analytically. To our knowledge, it is also too difficult to solve using standard optimization software, because the integer restrictions (brought on by integer division) pose serious problems to conventional optimization algorithms.

To find the maximum, it seems necessary to adopt a 'brute force' approach. We will attempt to cycle through all possible combinations of the ('reasonable') integer values for the inputs and then select out the combinations of inputs that bring about profit maximization. ${ }^{13}$ The profit-maximizing input sets are then recorded, and the time series will subsequently analyzed.

We now observe how the firm responds to changes in its market environment. This is modelled by seeing how the firm reacts to changes in the demand parameter $\beta$. Changes in $\beta$ can either stem from exogenous market developments or from the firm's own activity (e.g. advertising), and could correspond to the arrival of business opportunities assumed in the 'islands models' literature (Ijiri and Simon (1977), Sutton (1998), Bottazzi and Secchi (2006a)).

We therefore propose that demand follows the following simple growth process:

which firms can instantly and costlessly experience implausibly large increases in size. To this end one might introduce the existence of some sort of adjustment costs.

${ }^{13} \mathrm{Cycling}$ though all possible combinations would be extraordinarily computationally intensive. For example, if we allow variables $A-E$ to take any value from 0 to 100 , we end up with $100^{5}=10^{10}$ combinations. For this reason, we restrict ourselves to 'reasonable values' of the inputs. In choosing the initial conditions, we choose values for the inputs that are relatively close to the values obtained from optimization when the integer constraint is relaxed. If the values for any of the the inputs are on the bounds of the initial restrictions, we vary the possible values for the inputs accordingly. As demand increases, we assume the corresponding profit-maximizing set of inputs to be 'close' (if not equal) to those obtained in the previous step. 


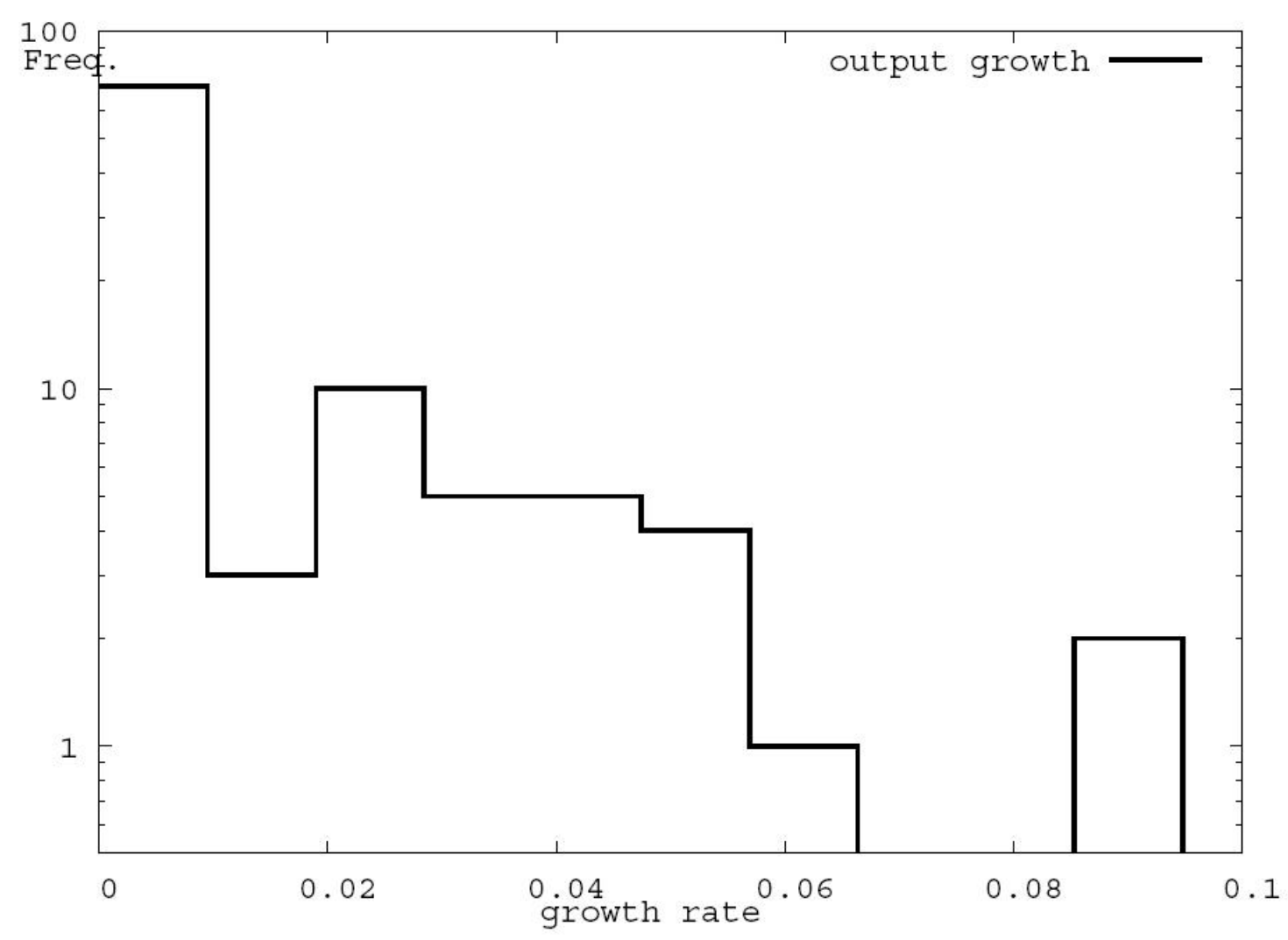

Figure 4: Distribution of growth rates of output $Q$. Note the log scale on the $y$ axis.

$$
\beta_{t+1}=(1.01) \beta_{t}
$$

which corresponds to a demand growth of $1 \%$ in each period $t$.

Given this dynamic demand, we will now observe the growth series of the profit-maximizing levels of inputs and total production. We will then observe the distribution of the resultant growth rates.

There is not much theoretical guidance available to help us with our parametrization. Concerning the input requirements, we assume: $r^{A}=1, r^{B}=0.14, r^{C}=0.09, r^{D}=0.022$, $r^{E}=0.003$. This implies that one production plant can efficiently house up to about 7 supervisors, about 30 machines, about 45 production workers and about 330 units of raw materials (corresponding to 330 production runs). Concerning the cost functions, we posit: $c^{A}=21, c^{B}=26, c^{C}=34, c^{D}=74, c^{E}=310$.

\subsection{Properties of the Model}

We now investigate some properties of the model. As is standard practice in simulation modelling, we let the model run for a short while before taking the readings. More specifically, 
Table 1: Cumulative distributions of the growth rate series.

\begin{tabular}{rrrrrr}
\hline & $\geq 0$ & $\geq 0.01$ & $\geq 0.02$ & $\geq 0.04$ & $\geq 0.08$ \\
\hline Growth of output $(Q)$ & 100 & 30 & 25 & 10 & 2 \\
Employment growth $(B$ and $D$ combined $)$ & 100 & 30 & 26 & 11 & 2 \\
Growth of machines $(C)$ & 100 & 23 & 23 & 14 & 2 \\
\hline \hline
\end{tabular}

we discard the first 50 periods and focus on the last 100 observations only.

\subsubsection{Growth rates distribution}

We consider first the distribution of growth rates. Table 1 presents some statistics on the cumulative distributions of some of the growth rate series. These results provide evidence of fat tails in the growth rate densities of output, employment, and machines. ${ }^{14}$ Figure 4 shows the distribution of growth rates of output. This figure provides further evidence on the fat tails of the growth rates distribution.

\subsubsection{Autocorrelation of growth rates}

Many studies, although not all, have found small negative autocorrelation in firm growth rates. $^{15}$ Autocorrelation coefficients from simple AR regressions are presented in Table 2. Regressions are performed using either OLS or least absolute deviation (LAD) techniques. OLS regressions suggest that, if anything, there is a mild negative autocorrelation, although median regressions (i.e. the LAD regressions) do not detect any autocorrelation. These simulated results are thus similar to the findings in Bottazzi et al. (2008) and Coad (2006) where growth rate autocorrelation is strongly negative on average (using OLS which calculates the 'average effect') whilst growth rate autocorrelation for the median firm (using LAD which calculates the 'median effect') is much closer to zero.

Coad (2007) presents a more detailed analysis of conditional growth rate autocorrelation using quantile autoregression techniques, which explore how growth rate autocorrelation varies over the conditional distribution of growth rates. Whilst for the average firm, growth rate autocorrelation is not so important, it is very important for the fast growth firms. Fast growth firms are quite unlikely to repeat their performance in the following year. As a result, the AR coefficient becomes very negative for these firms. Similarly, an analogous phenomenon affects extreme negative growth firms. The empirically observed autoregression profile is shown in the left panel in Figure 5. The right panel in Figure 5 shows a quantile autoregression plot for our simulated data. We view the comparison of these plots to be a (small) success story.

\footnotetext{
${ }^{14}$ Note that we do not report the results for growth of profits, because this series has a strong trending component, which comes from the nature of demand growth.

${ }^{15}$ See Coad (2007) for a survey.
} 

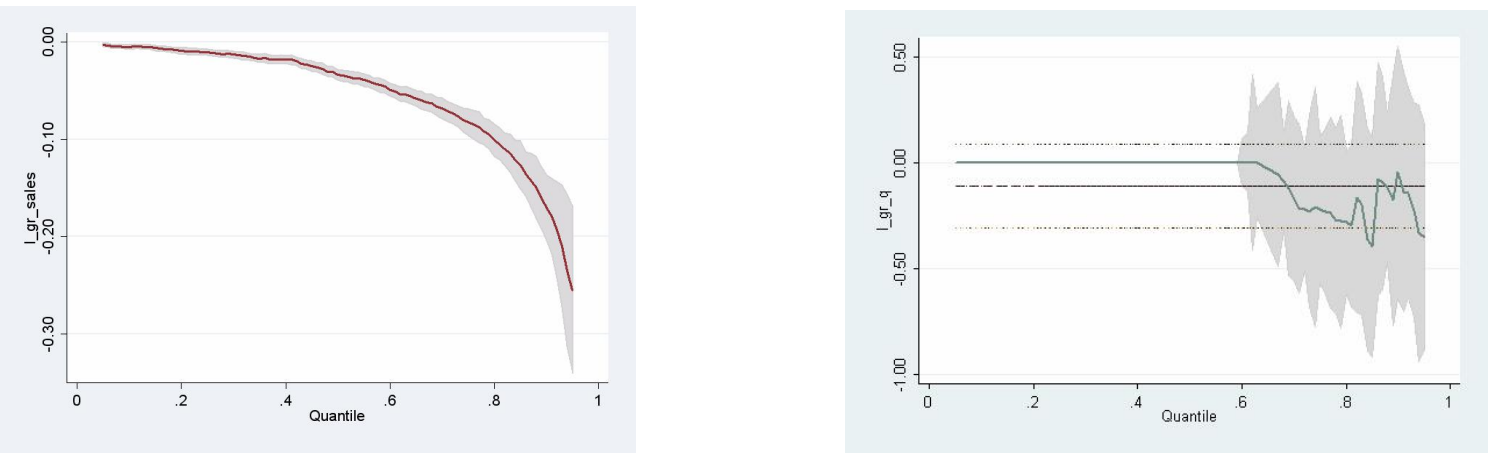

Figure 5: Quantile autoregression plots. Left: empirical quantile autoregression profile for sales growth, for firms with non-negative sales growth rates (source: author's elaboration based on Coad (2007) Figure 3 under the restriction of non-negative sales growth). Right: quantile autoregression profile of output growth for the simulated model. Both graphs show the variation in the coefficient on lagged growth of profits over the conditional quantiles of the growth rate distribution. Conditional quantiles (on the $x$-axis) range from 0 (for firms experiencing zero growth) to 1 (for the fastest-growing firms). Confidence intervals extend to $95 \%$ confidence intervals in either direction (right: confidence intervals obtained after 1000 bootstrap replications). Horizontal lines represent OLS estimates with 95\% confidence intervals. Graphs made using the 'grqreg' Stata module (Azevedo (2004)).

Table 2: Autocorrelation of growth rates of output.

\begin{tabular}{l|cccc} 
& Coefficient & $t$-stat & $R^{2}$ & obs \\
\hline (robust) OLS & -0.1102 & -1.41 & 0.0122 & 100 \\
LAD & 0.0000 & 0.00 & 0.0000 & 100 \\
\hline \hline
\end{tabular}

Whilst most firms experience no growth rate autocorrelation, it is the fastest growing firms (at the upper quantiles) that experience much stronger forces of negative autocorrelation. If a firm has just experienced widespread organizational growth, it is unlikely that it will grow in the following period. For such firms, growth can be accommodated by slack capacity.

\subsubsection{Scaling of growth rate variance with size}

Most studies into firm growth (but not all) have observed that the variance of growth rates decreases with firm size. ${ }^{16}$ Table 3 presents some evidence in this direction. When we split the sample into two groups according to size, the standard deviation decreases slightly (from 0.0221 to 0.0180 ). This has an intuitive explanation in the context of our model. The indivisibilities are larger with respect to a small firm's size than large firm's size, so smaller firms have a more 'jagged', erratic growth profile.

\footnotetext{
${ }^{16} \mathrm{~A}$ negative dependence of growth rate variance on size has been found in data on US manufacturing firms (Amaral et al. (1997); Bottazzi and Secchi (2003a)), for firms in the worldwide pharmaceutical industry (Bottazzi and Secchi (2006b)), and, to a lesser extent, for French manufacturing firms Bottazzi et al. (2008). In the case of Italian manufacturing firms, however, Bottazzi et al. (2007) do not observe any relationship
} 
Table 3: Scaling of variance with firm size.

\begin{tabular}{l|ccc|c} 
& Mean size $(Q)$ & Mean growth rate & Standard Deviation & Obs. \\
\hline First 50 periods & 184.18 & 0.012 & 0.0221 & 50 \\
Second 50 periods & 321.22 & 0.010 & 0.0180 & 50 \\
\hline \hline
\end{tabular}

\section{Conclusion}

We began this paper by observing that the distributions of growth rates of firms are distributed according to the Laplace distribution (also known as the symmetric exponential distribution). We then attempted to explain this emergent property. We acknowledge that there are many possible explanations for empirically observed regularities (Simon (1968)), especially for unconditional objects such as growth rate distributions (Brock (1999)). We therefore tried to base the assumptions of our model on theoretical descriptions of firm growth. While the Bottazzi and Secchi (2006a) model emphasizes competition between firms, our model focuses on the internal structure of business organizations to model the time series development of a single firm.

We drew upon insights from the resource-based view of the firm (Penrose (1959)) in order to present a class of models of firm growth. We viewed a firm as a coherent collection of complementary, discrete resources, that are subject to localised interactions, embedded in an organization that tends to a critical state of full utilization of resources. The lumpy nature of resources within a firm implies that firm expansion is characterized by nonconstant marginal costs that depend upon the degree of utilization of the firm's resources. In this context, a small stimulus working through local interaction channels can be transmitted throughout a firm to produce potentially large-scale effects.

In our first model we considered employment growth in the case of a hierarchical organization, in which a limit has been placed on the efficient span of control. We do not attempt to generalize upon where growth opportunities come from, but instead we consider how firms build upon growth opportunities. Adding an extra worker at the bottom of the hierarchy will marginally increase the workload at higher levels of the hierarchy, which may trigger off to a potentially large hiring of supervisors. It is observed that a firm's growth rate of total employment (productive workers and supervisors combined) will follow an exponential distribution.

Our second model was an attempt to extend the early model, by introducing fixed capital into the model. This model was capable of explaining a number of 'stylised facts' about firm growth, such as the heavy-tailed growth rates distribution, the peculiar shape of the 
conditional autocorrelation profile, and the scaling of growth rate variance with size. 


\section{References}

Amaral, L. A. N., Buldyrev, S. V., Havlin, S., Salinger, M. A., Stanley, H. E., and Stanley, M. H. R. (1997). Scaling behavior in economics: the problem of quantifying company growth. Physica A, 244:1-24.

Arthur, W. B. (1989). Competing technologies, increasing returns, and lock-in by historical events. Economic Journal, 99(394):116-131.

Ashton, T. S. (1926). The growth of textile businesses in the Oldham district, 1884-1924. Journal of the Royal Statistical Society, 89(3):567-583.

Azevedo, J. P. W. (2004). grqreg: Stata module to graph the coefficients of a quantile regression. Technical report, Boston College Department of Economics.

Bak, P. and Chen, K. (1991). Self-organizing criticality. Scientific American, January:26-33.

Bak, P., Chen, K., Scheinkman, J., and Woodford, M. (1993). Aggregate fluctuations from independent sectoral shocks: Self-organized criticality in a model of production and inventory dynamics. Richerche Economiche, 47(1):3-30.

Bottazzi, G., Cefis, E., and Dosi, G. (2002). Corporate growth and industrial structure: Some evidence from the Italian manufacturing industry. Industrial and Corporate Change, 11:705-723.

Bottazzi, G., Cefis, E., Dosi, G., and Secchi, A. (2007). Invariances and diversities in the patterns of industrial evolution: Some evidence from Italian manufacturing industries. Small Business Economics, 29(1):137-159.

Bottazzi, G., Coad, A., Jacoby, N., and Secchi, A. (2008). Corporate growth and industrial dynamics: Evidence from French manufacturing. Applied Economics, Forthcoming.

Bottazzi, G., Dosi, G., Lippi, M., Pammolli, F., and Riccaboni, M. (2001). Innovation and corporate growth in the evolution of the drug industry. International Journal of Industrial Organization, 19:1161-1187.

Bottazzi, G. and Secchi, A. (2003a). Common properties and sectoral specificities in the dynamics of US manufacturing companies. Review of Industrial Organization, 23:217-232.

Bottazzi, G. and Secchi, A. (2003b). A stochastic model of firm growth. Physica A, 324:213219.

Bottazzi, G. and Secchi, A. (2006a). Explaining the distribution of firms growth rates. Rand Journal of Economics, 37:234-263.

Bottazzi, G. and Secchi, A. (2006b). Gibrat's law and diversification. Industrial and Corporate Change, 37(2):235-256.

Brock, W. A. (1999). Scaling in economics: a reader's guide. Industrial and Corporate Change, 8(3):409-446.

Coad, A. (2006). A closer look at serial growth rate correlation. Pisa, Sant'Anna School of Advanced Studies, LEM Working Paper series 2006/29. 
Coad, A. (2007). A closer look at serial growth rate correlation. Review of Industrial Organization, 31(1):69-82.

Coad, A. and Rao, R. (2008). Innovation and firm growth in high-tech sectors: A quantile regression approach. Research Policy, 37(4):633-648.

Dixon, R. L. (1953). Creep. Journal of Accountancy, July:48-55.

Feldman, M. S. (2004). Resources in emerging structures and processes of change. Organization Science, 15(3):295-309.

Garnsey, E. (1998). A theory of the early growth of the firm. Industrial and Corporate Change, $7(3): 523-556$.

Geroski, P. A. and Gugler, K. (2004). Corporate growth convergence in Europe. Oxford Economic Papers, 56:597-620.

Hannan, M. T. (2005). Ecologies of organizations: Diversity and identity. Journal of Economic Perspectives, 19(1):51-70.

Ijiri, Y. and Simon, H. A. (1977). Skew Distributions and the Sizes of Business Firms. North Holland, Amsterdam.

Lesourne, J. (1973). Modeles de Croissance des Entreprises. Dunod, Paris.

Little, I. M. D. (1962). Higgledy piggledy growth. Bulletin of the Oxford University Institute of Statistics, 24(4):387-412.

McKelvey, B. and Andriani, P. (2005). Why Gaussian statistics are mostly wrong for strategic organization. Strategic Organization, 3(2):219-228.

Montgomery, C. A. (1994). Corporate diversification. Journal of Economic Perspectives, $8(3): 163-178$.

Penrose, E. T. (1959). The Theory of the Growth of the Firm. Basil Blackwell, Oxford.

Penrose, E. T. (1960). The growth of the firm - a case study: The Hercules powder company. Business History Review, 34(1):1-23.

Reichstein, T. and Jensen, M. (2005). Firm size and firm growth rate distributions - the case of Denmark. Industrial and Corporate Change, 14(6):1145-1166.

Simon, H. A. (1957). The compensation of executives. Sociometry, 20(1):32-35.

Simon, H. A. (1962). The architecture of complexity. Proceedings of the American Philosophical Society, 106(6):467-482.

Simon, H. A. (1968). On judging the plausibility of theories. In Logic, methodology and philosophy of science; proceedings of the international congress for Logic, Methodology and Philosophy of Science, pages 439-459. North-Holland, Amsterdam.

Stanley, M. H. R., Amaral, L. A. N., Buldyrev, S. V., Havlin, S., Leschhorn, H., Maass, P., Salinger, M. A., and Stanley, H. E. (1996). Scaling behavior in the growth of companies. Nature, 379:804-806. 
Starbuck, W. H. (1971). Organizational growth and development. In Starbuck, W. H., editor, Organizational Growth and Development, chapter 1, pages 11-141. Penguin books, Harmondsworth UK.

Sutton, J. (1998). Technology and Market Structure: Theory and History. MIT Press, Cambridge, MA.

Sutton, J. (2007). Market share dynamics and the 'persistence of leadership' debate. American Economic Review, 97(1):222-241.

Teece, D. J. (1986). Profiting from technological innovation: Implications for integration, collaboration, licensing and public policy. Research Policy, 15:285-305.

Weick, K. E. and Quinn, R. E. (1999). Organizational change and development. Annual Review of Psychology, 50:361-386.

Wernerfelt, B. (1984). A resource-based view of the firm. Strategic Management Journal, 5(2):171-180.

Williamson, O. (1967). Hierarchical control and optimum firm size. Journal of Political Economy, 75(2):123-138.

Winter, S. G. (1995). Four Rs of profitability: Rents, resources, routines, and replication. In Montgomery, C., editor, Resource-Based and Evolutionary Theories of the Firm: Towards a Synthesis. Kluwer Academic, Boston, MA. 